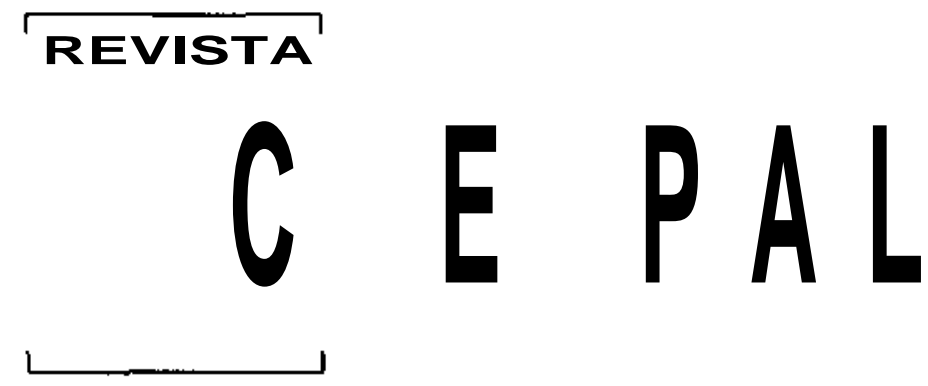

NUMERO 65

AGOSTO 1998

SANTIAGO DE CHILE

OSCAR ALTIMIR

Director

EUGENIO LAHERA

Secretario Técnico

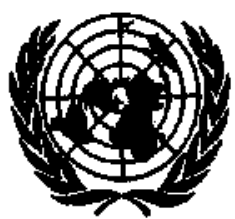

NACIONES UNIDAS 
Distribución del ingreso, pobreza y gasto social en América Latina José Antonio Ocampo

Gasto militar y el desarrollo en América Latina

Eugenio Lahera y Marcelo Ortúzar

Crecimiento, justicia distributiva y política social

Andrés Solimano

Equidad, inversión extranjera y competitividad internacional

Adolfo Figueroa

Tensiones en el ajuste estructural en América Latina: asignación vs. distribución

Daniel M. Schydlowsky

Competitividad y regulaciones laborales

Luis Beccaria y Pedro Galín

Familias latinoamericanas: convergencias y divergencias de modelos y políticas

Irma Amagada

Los acuerdos de libre comercio y el trabajo de las mujeres:

el caso de Chile

Alicia Frohmann y Pilar Romaguera

Evolución macroeconómica del Paraguay 1989-1997:

burbuja de consumo y crisis financiera

Stéphane Straub

Estrategias de las empresas mexicanas en sus procesos de internacionalización

Alejandra Salas-Porras

La regulación de la prestación privada de servicios de agua potable y alcantarillado

Terence R. Lee y Andrei S. Jouravlev

Promoción de la calidad para mejorar la competitividad

Hessel Schuurman

Publicaciones recientes de la CEPAL 


\section{Estrategias de las empresas mexicanas en sus procesos de internacionalización}

\section{Alejandra Salas-Porras \\ Facultad de Ciencias Políticas y Sociales, \\ Universidad Nacional \\ Autónoma de México}

Casi el $60 \%$ de los grupos no financieros más grandes de México desarrollan por lo menos dos tipos de actividades en tos mercados transnacionales. En este artículo se describen y analizan diversas trayectorias y estrategias de internacionalización de tas empresas mexicanas. Este impulso a la internacionalización se da en el marco de una economía abierta orientada a la exportación y de la creciente integración con los Estados Unidos y Canadá. Diversos factores nacionales e internacionales, y otros propios de las empresas, influyen en las estrategias elegidas y sus resultados. El artículo consta de una introducción (sección I) y seis secciones en las que se examinan los distintos caminos seguidos por las empresas mexicanas para convertirse en transnacionales. En ellas se identifican las empresas que han establecido filiales en países desarrollados (sección II). Se pasa revista a las que han recurrido a alianzas estratégicas que podrían llevarlas a convertirse en empresas transnacionales, y se destacan algunos casos sobresalientes de este tipo (sección III). Se describe la presencia de empresas mexicanas en los mercados de valores internacionales y la interacción que ella supone con las instituciones financieras mundiales (sección IV). Se analizan las estrategias seguidas por algunas empresas mexicanas para articular redes globales de comercio (sección V). Se examina la rápida expansión de las soluciones y estrategias que aplican las empresas para lograr una posición mundial (sección VI). Y por último se formulan algunas conclusiones en las cuales se evalúan las trayectorias y preferencias de las empresas mexicanas en su afán de convertirse en empresas transnacionales, los obstáculos que tuvieron que superar y las consecuencias de su gestión internacional (sección VII). 


\section{Introducción}

El presente artículo describe el proceso que han seguido las empresas mexicanas en su intento por actuar en el escenario inlernacional, es decir, por llegar a un estado en que su gestión se verá reglamentada, moldeada y modificada no sólo, o no fundamentalmente, por el devenir nacional. Ejerce creciente influencia sobre su estructura organizacional y su gestión empresarial la mayor interacción y retroalimentación con las instituciones y agentes transnacionales que operan a través de las redes manufactureras, financieras, comerciales y empresariales que han logrado un alcance mundial.

Se pretende en este artículo averiguar qué empresas mexicanas se han convertido en empresas transnacionales y qué estrategias adoptaron para conseguirlo; cómo los empresarios mexicanos, en virtud de su gestión y estrategias transnacionales se convierten en actores del mercado mundial y modifican las limitaciones estructurales que constriñen el alcance de su gestión y de su organización empresarial; en qué medida superan esas limitaciones; y por qué reformaron sus estrategias sólo al terminar el decenio de 1980, cuando otros países de industrialización reciente (como los tigres asiáticos, por ejemplo) habían hecho grandes adelantos en este sentido en una época anterior (Tseng, 1994). En otras palabras, se trata de averiguar qué fuerzas pusieron en marcha este proceso.

Todo el artículo está enfocado desde el punto de vista del agente: un agente que está bien informado sobre el significado de la actual coyuntura, y sobre los costos y posibilidades que implica la transición a una situación global. A este mismo nivel se plantearán otros asuntos: cómo los empresarios mexicanos desafían y reaccionan ante las formas, condiciones y reglas que rigen su interacción con el sistema mundial; cómo expresan y activan una motivación estratégica y consciente de ingresar al mercado internacional, para interactuar y competir con fuerzas globales, planificar su gestión $\mathrm{y}$, en forma creciente, su misma estructura organizacional.

Dado este enfoque, la definición de las empresas transnacionales empleada en este artículo por fuerza debe subrayar el fundamento estratégico en que descansa la gestión global, y al mismo tiempo debe ser operativo. Así, para los fines del presente análisis, la empresa transnacional se define como una compleja organización comercial que ha ampliado su ámbito de gestión a varios países aplicando por lo menos dos de las estrategias siguientes:

i) Manejo de filiales: generalmente para conquistar una posición mundial en determinados productos, para ganarle a la competencia y al mismo tiempo para defender sus propios mercados de importaciones masivas o dumping. Este nuevo énfasis en el posicionamiento en el mercado y cotejo con normas internacionales de excelencia será de primordial importancia al planificar el crecimiento. Por lo tanto, las empresas mexicanas que lleguen al mercado global deben medir su grado de competencia y mejorarlo, no con relación a las normas nacionales, sino frente a sus competidores mundiales más cercanos.

ii) Afianzas estratégicas: combinaciones múltiples y diversificadas con las empresas transnacionales de los países desarrollados y en vías de desarrollo, lo que implica segmentación, especialización, redistribución sectorial y/o geográfica de los mercados; combinación de redes de distribución, administración tecnológica, y conocimientos de comercialización; e intercambio de ejecutivos y directores. La naturaleza del enlace va más allá de la que exigía el joint venture, o las licencias de tecnología o comercialización de los decenios de 1960 у 1970.

iii) Colocación de acciones y otros valores en los mercados extranjeros, lo que exige, por una parte, refinados sistemas de información y comunicación con los inversionistas institucionales, la banca de inversiones, los corredores de la bolsa y otros agentes especializados, y, por la otra, una actitud más abierta hacia el público en general y los inversionistas en particular (acreedores, gerencia, clientes, consumidores, empleados y accionistas).

iv) Creación de redes: redes de distribución o comercialización establecidas por la empresa para promover y comercializar sus propios productos $\mathrm{u}$ otras exportaciones mexicanas, sobre todo a los Estados Unidos, pero también a otros países industrializados. Ya no dependen de agentes o corredores para exportar y han logrado una gran diversificación de sus ingresos.

Muchas empresas mexicanas grandes y pequeñas están explorando caminos para abrir nuevos mercados y es difícil en este momento predecir si tendrán éxito. Con el criterio de la diversificación en los mercados ex- 
tranjeros (en por lo menos dos tipos de actividades) he intentado verificar que efectivamente están afianzadas en la economía mundial y que están más profundamente comprometidas con las reglas del mercado global.

Todas estas actividades presuponen una interacción intensa y la planificación colectiva con los agentes mundiales de los países capitalistas avanzados. El intercambio de informaciones y la comunicación con los clientes, proveedores, inversionistas, acreedores, socios y aliados comerciales hacen que sea muy complejo el proceso de planificación y toma de decisiones colectivo, pero es un proceso necesario. Esta interacción, por su parte, influye sobre la gestión y promueve estrategias y modalidades de comportamiento muy difundidas entre los países capitalistas avanzados. Sin embargo, y como veremos más adelante, suscita dificultades y contradicciones que exigen respuestas sofisticadas, planificación a corto y mediano plazo y una vigilancia meticulosa de todas sus actividades en México y en el extranjero. En otras palabras, en vez de la reacción espontánea a las señales de) mercado y a la política pública, se da un proceso cada vez más complejo de planificación y toma de decisiones estratégicas. Sin este proceso, no sería posible integrar las actividades nacionales y transnacionales, ni coordinar las alianzas y redes empresariales internalizadas y externalizadas. No sería ni siquiera posible vigilar todas sus actividades ni mucho menos cumplir las normas de su nuevo medio global. En este proceso de planificación colectiva estratégica en que se basa su acción transnacíonal radica, en mi opinión, la principal diferencia con respecto a cualquier otra participación anterior por estas empresas en los mercados internacionales y no, como dice Peres Núñez (1993, p. 56) en un viraje desde el comercio exterior y el endeudamiento hacia la inversión extranjera directa. ${ }^{2}$

\section{II}

\section{Establecimiento de filiales}

Desde el decenio de 1970 las empresas mexicanas han ampliado sus operaciones hacia otros mercados del tercer mundo, en una estrategia predominantemente defensiva, destinada a proteger los mercados de exportación, dar un alivio a la contracción de la demanda en México, diversificar las fuentes de ingreso externo o por lo menos reducir la dependencia de un solo país. En el decenio de 1990, en cambio, las empresas penetraron en los mercados industrializados y rápidamente lograron afianzarse con un alto ranking en sus campos de operación específicos. El cuadro 1 muestra que de los 60 grupos no financieros más grandes ${ }^{3}$ sólo trece tienen filiales operativas (es decir, con actividades que rinden valor agregado) en los países industrializados, aunque muchas más tienen perspectivas o buscan posibilidades de crecimiento por medio de fusiones y adquisiciones.

\footnotetext{
1 Es decir, vinculaciones con compañías que pertenecen o no a la empresa.

${ }^{2}$ Como se verá más adelante, se ha modificado dramáticamente el tipo de inserción de las empresas mexicanas en los mercados internacionales. Aunque anteriormente no faltaba la inversión extranjera, se orientaba más bien a los países de menor desarrollo relativo, o en la forma de inversiones indirectas o en bienes raíces, a los países capitalistas avanzados.
}

Sería difícil seguir la evolución de cada caso. He preferido examinar tres casos claves en mayor detalle (Vitro, Cemex y Televisa) por distintas razones: todos manifestaron su intención de internacionalizarse e informaron sobre las medidas que tomarían para lograr ese objetivo; todas han seguido estrategias muy agresivas para ampliar sus actividades hacia otros países, ganar una posición internacional e integrar sus operaciones para aprovechar la sinergia y ventajas específicas de la empresa; y una gran proporción de sus ingresos y valor agregado se origina en el exterior. ${ }^{4}$

Vitro se expandió al mercado de los Estados Unidos con la adquisición de Anchor Glass y Latchford Glass en 1989 y se convirtió en el segundo mayor pro-

\footnotetext{
3 A fin de examinar los principales medios de desarrollo de las grandes empresas y las estrategias que siguieron para internacionalizarse, preparé una lista de los grupos no financieros más grandes del país y otra de los 15 grupos financieros más importantes, medidos por las venias y activos (principales criterios usados para ordenar los grupos no financieros y financieros; respectivamente). La lista se preparó sobre la base de los ingresos por ventas y los activos de 1994 consignados en Expansión 500, la bolsa de valores mexicana y los informes anuales de las empresas.

4 A menos que se especifique otra cosa, la información proviene de entrevistas (véase la lista de entrevistas al final del artículo), informes de asambleas anuales y circulares de ofrecimiento.
} 
ductor de contenedores de vidrio de ese país, con una participación del 40 por ciento de las ventas totales de Vitro en 1990, 59 por ciento en 1992 y 56 por ciento en 1993. La transacción significó para el grupo aprender nuevas y sofisticadas reglas de juego. En México las adquisiciones se suelen dar a través de negociaciones amistosas. Era la primera vez que una empresa mexicana intentaba la compra hostil de una firma estadounidense y, según los analistas de Wall Street, el precio fue "más que generoso", sobre todo si se considera que Anchor había reportado pérdidas el año anterior y que la industria del vidrio estaba en crisis, frente a la fuerte competencia de los contenedores de plástico. ${ }^{5}$ Durante las negociaciones los altos ejecutivos de Vitro manifestaron su deseo de convertirse en empresa transnacional: "Si queremos seguir siendo una empresa fabricante de vidrio, como lo hemos sido por 80 años, no podemos ya contentarnos con una fuerte base de mercado nacional y alguna actividad exportadora", dijo Ernesto Martens, Gerente Genera!, antes de concluir el negocio \{The New York Times, 1989 y Wall Street Journal, 1989). Sin embargo, para 1997 había fracasado el proyecto y Vitro tuvo que vender sus inversiones en Anchor y replegarse al mercado mexicano.

La expansión de Cemex al mercado internacional se logró también principalmente por medio de adquisiciones. En 1995 las ventas generadas fuera de México (sumando las exportaciones y el ingreso de operaciones internacionales) representaban casi la mitad del ingreso total de Cemex. En 1989 el grupo compró varias compañías en Texas y California que le significaron conquistar una décima parte del mercado de esos estados occidentales. En 1992 Cemex pagó 1850 millones de dólares por las dos fábricas más grandes de cemento de España - La Valenciana y Sansón - que representaban un 28 por ciento del mercado español.

Los círculos allegados a las bolsas de valores internacionales - sobre todo los que vigilaban las acciones latinoamericanas - consideraron que esta adquisición era muy riesgosa porque la compañía tenía escasa experiencia en las operaciones de ultramar y significaba aumentar su deuda a largo plazo en 760 millones de dólares y los créditos inmediatos en 1350 millones.

Los inversionistas estadounidenses y europeos, que recientemente habían adquirido acciones de Ce-

\footnotetext{
5 La oferta original era de 251.4 millones de dólares y el costo final llegó a 390 millones por el capital y 460 millones por la deuda (un total de 900 millones incluyendo a Latchford Glass).
}

mex, protestaron de una decisión que consideraban arbitraria y unilateral, de la que no se les había informado debidamente en anteriores prospectos y presentaciones. Dos días después de anunciar la operación, el precio de las acciones de Cemex cayó en 17 por ciento, ${ }^{6}$ La decisión de los agentes de los mercados de valores de deshacerse de las acciones de Cemex indujo a los más altos ejecutivos de la compañía a organizar varias presentaciones para demostrar que su estrategia era racional y prometedora. Sin embargo, la comunidad comercial siguió dudando por algún tiempo de la capacidad empresarial de Cemex para operar en los mercados europeos (entrevista 2).

A pesar de la desconfianza y oposición de la comunidad del mercado de valores, la gerencia de Cemex siguió adelante con una estrategia agresiva, De 1993 a 1996 el grupo amplió su gestión considerablemente en América del Sur y Central. Hacia 1996 su esfera de influencia abarcaba 20 países (véase el cuadro 1). Como motivo de esa estrategia agresiva, estaba nuevamente !a decisión de Cemex de convertirse en empresa transnacional y al mismo tiempo defender sus mercados tanto dentro como fuera de México. "La industria mundial del cemento se concentra cada día más y tenemos que estar con la vanguardia", señaló Lorenzo Zambrano, Gerente General y principal accionista (Financial Times, 1992). La demanda espectacular de bonos Cemex en mayo de $1993^{7}$ demostró que a la postre la estrategia del grupo fue aprobada por la comunidad financiera mundial.

Televisa, la compañía de televisión y medios de comunicación, también tuvo que pelear su ingreso al mercado de los Estados Unidos. Los primeros dos intentos - -Spanish International Network (SIN) y The National- fueron infructuosos. En 1986 se acusó al grupo de prácticas ilícitas. Tuvo que afrontar una compleja disputa legal. La Comisión Federal de Comunicaciones de los Estados Unidos alegaba que la compañía violaba disposiciones sobre propiedad extranjera. ${ }^{8}$ Emilio Azcárraga Milmo vendió las estaciones a Hallmark Cards Inc., quienes acordaron mantener la misma estructura de administración. El grupo se vio así obligado a retirarse, parcial y temporalmente al menos, de la red televisiva en español de los Estados Unidos.

6 Véase Euromoney (1993) y Financial Times (1992).

7 Véase la sección sobre los mercados mundiales de valores.

${ }^{8}$ La legislación de los Estados Unidos prohibe que más de un 20 por ciento del capital de una estación de televisión sea de propiedad extranjera. 
CUADRO 1

México: Filiales en otros países de empresas mexicanas

\begin{tabular}{|c|c|c|c|c|}
\hline Grupo & Filial & País & Año & Procedimiento \\
\hline Vitro & $\begin{array}{l}\text { Anchor }(100 \%) \\
\text { Latchford }(100 \%)\end{array}$ & $\begin{array}{l}\text { Estados Unidos } \\
\text { Estados Unidos }\end{array}$ & $\begin{array}{l}1989 \\
1989\end{array}$ & $\begin{array}{l}\text { Compra hostil } \\
\text { Adquisición }\end{array}$ \\
\hline $\begin{array}{l}\text { Carso- Global } \\
\text { Telecom }\end{array}$ & $\begin{array}{l}\text { International } \\
\text { Wireless } \\
\text { Prodigy }\end{array}$ & $\begin{array}{l}\text { Estados Unidos } \\
\text { España }\end{array}$ & 1996 & Fusión y adquisición \\
\hline $\begin{array}{l}\text { Cemex } \\
\text { (20 países) }\end{array}$ & $\begin{array}{l}\text { Sunbelt } \\
\text { Pacific Coast } \\
\text { La Valenciana } \\
\text { Sansón } \\
\text { Vencemos } \\
\text { Bayano } \\
\text { Diamante } \\
\text { Samper }\end{array}$ & $\begin{array}{l}\text { Estados Unidos } \\
\text { Estados Unidos } \\
\text { España } \\
\text { España } \\
\text { Venezuela } \\
\text { Panamá } \\
\text { Colombia } \\
\text { Colombia }\end{array}$ & $\begin{array}{l}1989 \\
1989 \\
1992 \\
1992 \\
1994 \\
1994 \\
1996 \\
1996\end{array}$ & $\begin{array}{l}\text { Adquisición } \\
\text { Adquisición } \\
\text { Adquisición } \\
\text { Adquisición } \\
\text { Adquisición } \\
\text { Adquisición } \\
\text { Adquisición } \\
\text { Adquisición }\end{array}$ \\
\hline $\begin{array}{l}\text { Visa } \\
\text { Ica } \\
\text { Televisa }\end{array}$ & $\begin{array}{l}\text { Coca-Cola }(51 \%) \\
\text { Rodio } \\
\text { Univisión } \\
\text { Galavisión } \\
\text { Televicine España } \\
\text { Cía. Peruana } \\
\text { Telev. Argentina } \\
\text { Telev. Bolivia } \\
\text { Telev. Chile } \\
\text { Venevisión }\end{array}$ & $\begin{array}{l}\text { Argentina } \\
\text { España } \\
\text { Estados Unidos } \\
\text { Estados Unidos } \\
\text { España } \\
\text { Perú } \\
\text { Argentina } \\
\text { Bolivia } \\
\text { Chile } \\
\text { Venezuela }\end{array}$ & 1994 & $\begin{array}{l}\text { Adquisición } \\
\text { Adquisición }\end{array}$ \\
\hline Bimbo & $\begin{array}{l}\text { Baird's, QFS }(50 \%) \\
\text { Salimentos Alesa } \\
\text { Bímbo } \\
\text { Bimbo } \\
\text { Bimbo } \\
\text { Bimbo } \\
\text { Marínela }\end{array}$ & $\begin{array}{l}\text { Estados Unidos } \\
\text { Chile } \\
\text { Costa Rica } \\
\text { Argentina } \\
\text { Honduras } \\
\text { El Salvador } \\
\text { Venezuela } \\
\text { América Central }\end{array}$ & 1994 & Adquisición \\
\hline $\begin{array}{l}\text { Gruma } \\
\text { Imsa }\end{array}$ & $\begin{array}{l}\text { Maseca } \\
\text { Acumulad Fulgor } \\
\text { Acumulad Indust } \\
\text { Durex Indust } \\
\text { Stabilit } \\
\text { IMSA } \\
\text { Enermex }\end{array}$ & $\begin{array}{l}\text { Estados Unidos } \\
\text { Venezuela } \\
\text { Venezuela } \\
\text { Brasil } \\
\text { Argentina } \\
\text { Chile } \\
\text { Brasil }\end{array}$ & $\begin{array}{l}1993 \\
1993 \\
1994\end{array}$ & $\begin{array}{l}\text { Planta nueva } \\
\text { Adquisición } \\
\text { Adquisición } \\
\text { Planta nueva }\end{array}$ \\
\hline Dina & & & & \\
\hline Synkro & $\begin{array}{l}\text { Kayser-Roth } \\
\text { Modeeraft }\end{array}$ & $\begin{array}{l}\text { Estados Unidos } \\
\text { Argentina }\end{array}$ & $\begin{array}{l}1993 \\
1993\end{array}$ & $\begin{array}{l}\text { Adquisición apalancada } \\
\text { Adquisición }\end{array}$ \\
\hline $\begin{array}{l}\text { lusacell } \\
\text { Herdez }\end{array}$ & Festin Food & Estados Unidos & 1990 & Adquisición \\
\hline
\end{tabular}

Fuentes: América Economía (1993-1994), Infosel, Reuters y memorias anuales de las compañías inscritas en la Bolsa de Valores de México,

Poco tiempo después, Televisa intentó nuevamente penetrar en el mercado televisivo de los Estados Unidos, pero esta vez con un aliado distinto. Asociada con Jerrold Perrenchio, de California (que compartiría 75 por ciento de los canales de televisión y 50 por ciento de la red) y Gustavo Cisneros (presidente de Venevisión), que tendría la misma participación que Televisa, la compañía logró la aprobación de la Comisión Federal de Comunicaciones (Expansión, 1992).

Univisa controla la distribución de las ventas internacionales de los programas de Televisa en español, lo que implica que el grupo soslayó las restricciones sobre la propiedad de extranjeros en los Estados Unidos al vender sus programas a un grupo de canales sobre los cuales ejerce control empresarial. Así, aunque fueron parcial y temporalmente impedidos de manejar estaciones de televisión, el grupo maniobró de tal forma que a la postre recuperó y fortaleció su participación en el mercado televisivo en español de los Estados Unidos. Hoy este imperio de los medios de comunicación cubre un 90 por ciento de la red de habla hispana de Norteamérica, más un 18 por ciento del 
mercado español $\mathrm{y}$, con una serie de joint ventures ha ingresado a los mercados de Chile, Perú, Argentina y Venezuela (véase el cuadro 1). Es el primer productor del mundo de programas de televisión de habla hispana (entrevista $\mathrm{N}^{\circ} 7$ ).

Otras empresas mexicanas tienen filiales que operan en los Estados Unidos u otros países industrializados aunque no han alcanzado posiciones importantes. Las que han logrado transnacionalizarse, han tenido que luchar por avanzar y defender su lugar en el mercado nacional e internacional; han tenido que emplear distintas estrategias de inversión; negociar con distintas reglas; aprender prácticas financieras, jurídicas y fiscales diferentes; y operar en un marco institucional mucho más agresivo $y$ estrictamente reglamentado.

Y aunque contaran con el asesoramiento de equipos especiales de consultores y consejeros financieros, la gestión ha sido compleja y peligrosa. Los nuevos proyectos han exigido muy poca nueva inversión mexicana real (a veces nada), pero como enseña el fracaso de Vitro en la industria del vidrio estadounidense, jos nuevos empresarios se están jugando los recursos acumulados en un largo período histórico.

\section{III}

\section{Del joint venture convencional}

\section{a la alianza estratégica}

No existe aún acuerdo en torno a la definición de una alianza estratégica. Siendo una de las nuevas prácticas más características de la acción global, es necesario identificar algunos de sus rasgos más sobresalientes para poder evaluar el grado en que las alianzas mexicanas han sido realmente estratégicas.

La bibliografía sobre el tema tiende a enfatizar la cooperación, la colaboración y la complementariedad como los principios que orientan la formación de este tipo de alianza. Se supone que las redes de alianzas estratégicas son autorreguladas y no jerárquicas, que el conflicto casi no se da, considerándose anormal y raro cuando aparece (After y Hage, 1993; pp. 189-195). La escasa atención que prestan los investigadores al conflicto puede tener su origen en parte en el hecho de que todos los autores se han concentrado en las alianzas estratégicas entre empresas transnacionales con sede en países capitalistas desarrollados. Es probable que éstas negocien en condiciones de igualdad. Por lo tanto, sería difícil a estas alturas llegar a una definición que incluya las particularidades de las alianzas entre empresas de países avanzados y de países de industrialización reciente, ya que este tipo de alianzas es un fenómeno relativamente reciente y rápidamente cambiante entre empresas de distinto tamaño y poder. No obstante, pueden señalarse algunas de las características más importantes de las alianzas estratégicas, a saber: i) una combinación de ventajas y activos; ii) un proceso gradual, y a menudo en numerosas etapas, de deliberación para generar consenso, un fuerte sentido de interés común y aplicación de prácticas activas y colectivas de administración; y iii) la necesidad de lograr el control y la adaptación locales al medio económico y cultural nacional (Alter y Hage, 1993 y Lorange y Roos, 1992).

En el caso particular de las alianzas de empresas mexicanas, la red de compañías aliadas es muy dinámica y contradictoria como se verá más adelante. Sin embargo, la necesidad de lograr ventajas complementarias acerca mucho más a las empresas nacionales y extranjeras; el socio mexicano generalmente busca ser más activo en el ámbito internacional, ganar acceso a los mercados externos y a la tecnología de punta, en tanto que el socio extranjero busca aprovechar el potencial de crecimiento mexicano (Jurgensen, 1993).

Algunas de las alianzas estratégicas más importantes llevadas a cabo por empresas mexicanas recientemente revelan no sólo el alcance de la relación, sino la fuerza - y, como se verá, también las debilidadesde los nuevos agentes transnacionales mexicanos. Muestran también una redistribución sectorial y una segmentación de mercados de creciente importancia a la luz del Tratado de Libre Comercio de América del Norte (NAFTA) y la formación del mercado regional norteamericano.

Como se aprecia en el cuadro 2, el número de afianzas ha crecido rápidamente en los últimos años. Sin embargo, sólo pocas tienen un perfil estratégico nítido, como un acuerdo de objetivos múltiples, combinando la manufactura, la distribución, la comercialización, la inversión y los recursos organizacionales. 
CUADRO 2

México: Alianzas estratégicas de empresas mexicanas

\begin{tabular}{|c|c|c|c|c|}
\hline Grupo mexicano & Socio(s) & Origen & Año & Sector \\
\hline \multirow[t]{3}{*}{ Telmex } & Southwest Bell ${ }^{\mathrm{a}}$ & Estados Unidos & 1991 & Comunicaciones \\
\hline & France Telecom ${ }^{\mathrm{a}}$ & Francia & 1991 & Comunicaciones \\
\hline & Sprint $^{11}$ & Estados Unidos & 1996 & Multimedios \\
\hline Cifra & Wal-Mart" & Estados Unidos & 1991 & Comercio minorista \\
\hline \multirow[t]{2}{*}{ Vitro } & Ford & Estados Unidos & & Vidrio \\
\hline & Pilkington & Estados Unidos & & Vidrio \\
\hline Famosa & Owens & Estados Unidos & & Equipos \\
\hline Vitiocrisa & Corning $^{\mathrm{ab}}$ & Estados Unidos & $1991^{a}$ & Eq. eléctricos \\
\hline Vitroerisa & WTI & Estados Unidos & 1992 & Eq. para el hogar \\
\hline \multirow[t]{3}{*}{ Acras } & Whirlpool $^{\mathrm{a}}$ & Estados Unidos & 1992 & Cont. de aluminio \\
\hline & American Silver & Estados Unidos & 1991 & Petroquímica \\
\hline & Pechiney & Francia & 1994 & \\
\hline \multirow[t]{6}{*}{ Cydsa } & BF Goodrich & Estados Unidos & & \\
\hline & Royal Plastics & & & \\
\hline & Mitsubishi & & & \\
\hline & Bayer & & & Medio ambiente \\
\hline & Allied Signal & & & \\
\hline & Dora Olver & & & \\
\hline San Marcos & Crown Crafts & Estados Unidos & 1993 & \\
\hline \multicolumn{5}{|l|}{ Carso } \\
\hline Nacobre & Modine & & & \\
\hline Ciatam & Philip Morris & Estados Unidos & 1993 & Tabaco \\
\hline \multirow[t]{2}{*}{ Euskadi } & General Tire & Alemania & 1993 & Neumáticos \\
\hline & Continental AG & Canadá & & Minería \\
\hline Frisco & Placer Dome & & & \\
\hline \multirow[t]{2}{*}{ Cemex } & Mobley's Environ't & & 1992 & Energía \\
\hline & Scancem & & 1993 & Dist. de cemento \\
\hline \multirow[t]{4}{*}{ Alfa } & MANGHH & Estados Unidos & 1980 & Tecnología \\
\hline & Shaw & Estados Unidos & 1994 & Alfombras \\
\hline & $\mathrm{AT} \& \mathrm{~T}$ & Estados Unidos & 1995 & Comunicaciones \\
\hline & Payless Cashways & Estados Unidos & 1993 & Dist. minorista \\
\hline \multirow[t]{2}{*}{ Sigma } & Oscar Mayer & Estados Unidos & 1993 & Distribución \\
\hline & Sodima & France & 1993 & Yogurt \\
\hline \multirow[t]{2}{*}{ Petrocel } & Himont & Estados Unidos & 1992 & Petroquímica \\
\hline & Eastman Chemical & & 1995 & Productos químicos \\
\hline \multirow[t]{5}{*}{ Alpek } & Akzo & Estados Unidos & 1975 & Fibras sintéticas \\
\hline & Dupont & Dinamarca & 1976 & Fibras sintéticas \\
\hline & Basf & Alemania & 1975 & Petroquímica \\
\hline & Celanese & México & & Petroquímica \\
\hline & Amoco & Estados Unidos & 1987 & Petroquímica \\
\hline \multirow[t]{2}{*}{ Hylsa } & Worthington & & 1994 & Acero \\
\hline & Metecno & España & 1993 & Acero \\
\hline Ademsa & Bekaert & Bélgica & 1993 & Metales \\
\hline \multirow[t]{2}{*}{ Gigante } & Flemining & Estados Unidos & 1992 & Dist. minorista \\
\hline & Carrefour & Francia & 1994 & \\
\hline Radio Shack & Tandy & Estados Unidos & & Dist. minorista \\
\hline \multicolumn{5}{|l|}{ Visa } \\
\hline Femsa & Coca-Cola ${ }^{\mathrm{a}}$ & Estados Unidos & 1993 & Bebidas \\
\hline Femsa & Miller Brewing & Estados Unidos & 1993 & Cerveza \\
\hline Comercial mexicana & Price Club & Estados Unidos & 1991 & Dist. minorista \\
\hline & $\mathrm{ABB}$ & & & \\
\hline & Knoll Int. & Estados Unidos & 1993 & Construcción \\
\hline & Fluor Daniel & Estados Unidos & 1992 & Ingeniería \\
\hline & General Electric & Estados Unidos & 1992 & Hidroenergía \\
\hline & Con Perini ${ }^{\mathrm{a}}$ & Estados Unidos & 1992 & Almacenan. agua \\
\hline & O\&G Ind. & Estados Unidos & & \\
\hline & GEC Alsthom & Francia & 1992 & Termoenergía \\
\hline & Duro Felguera & España & 1992 & Bienes de capital \\
\hline & WMX Tech & Estados Unidos & 1992 & Medio ambiente \\
\hline & Gral des Eaux & Francia & & Medio ambiente \\
\hline & Souletanche & Francia & 1994 & Construcción \\
\hline & Bechtel & Estados Unidos & & Construcción \\
\hline & Florida Roads ${ }^{\mathrm{a}}$ & & & \\
\hline & Sheraton & Estados Unidos & & Hoteles \\
\hline
\end{tabular}

(Continúa en página siguiente) 
Cuadro 2 (continuación)

\begin{tabular}{|c|c|c|c|c|}
\hline Grupo mexicano & Socio(s) & Origen & Año & Sector \\
\hline \multirow[t]{12}{*}{ Televisa } & Megavisión & Chile & 1991 & TV medio \\
\hline & Venevisión & Venezuela & 1991 & TV medio \\
\hline & Cía. Argentina & Argentina & 1992 & TV medio \\
\hline & Cía. Peruana & Perú & 1992 & TV medio \\
\hline & TCI & Estados Unidos & 1993 & TV cable \\
\hline & Discovery Cormm $^{a}$ & Estados Unidos & 1993 & TV programación \\
\hline & Sociedad Europa ${ }^{a}$ & & 1993 & Transmisión \\
\hline & News Corp. & Australia & 1993 & TV programación \\
\hline & Hearst $^{\mathrm{a}}$ & Estados Unidos & 1993 & Publicación revista \\
\hline & Pan Ain $\mathrm{Sat}^{\mathrm{a}}$ & Estados Unidos & 1992 & Satélite \\
\hline & QVC Network & & 1993 & Telemarketing \\
\hline & Fox Broadcasting & & 1994 & \\
\hline Aeroméxico & Air France ${ }^{\mathrm{a}}$ & Francia & 1993 & Transporte \\
\hline \multirow[t]{2}{*}{ Gdmodelo } & Anheuser-Busch ${ }^{\mathrm{a}}$ & Estados Unidos & 1993 & Cerveza \\
\hline & Bambrini $^{\mathrm{a}}$ & Estados Unidos & & Distribución \\
\hline \multirow[t]{2}{*}{ Bimbo } & Sara Lee ${ }^{a}$ & Estados Unidos & 1992 & Distribución \\
\hline & Baird's Bak ${ }^{\mathrm{a}}$ & Estados Unidos & 1994 & Alimentos \\
\hline \multicolumn{5}{|l|}{ Desc } \\
\hline \multirow[t]{6}{*}{ Spicer } & Dana Corp. ${ }^{\mathrm{a}}$ & Estados Unidos & $70-93$ & Repuestos autom. \\
\hline & Kelsey Hayes & & & Metal \\
\hline & GKN & & & Repuestos autom. \\
\hline & GM & & & Repuestos autom. \\
\hline & TRW & & & Repuestos autom. \\
\hline & Cabot & & & \\
\hline Liverpool & K-Mart & Estados Unidos & 1993 & Dist. minorista \\
\hline Tin rusa & JB Hunt ${ }^{\mathrm{a}}$ & Estados Unidos & 1992 & Transporte \\
\hline \multirow[t]{2}{*}{ Imsa } & Nicholas Plastics & Estados Unidos & 1993 & Repuestos autora. \\
\hline & Durlex Ind. & Brasil & 1994 & Repuestos autom. \\
\hline Aty & Car Sprint & & & \\
\hline Ahmsa & & Holanda & & \\
\hline \multirow[t]{3}{*}{ Ggnex } & Pepsico & Estados Unidos & & Bebidas \\
\hline & Natural Beverage & Canadá & 1993 & Distribución \\
\hline & Seagrams & Canadá & 1993 & Bebidas \\
\hline Sidek & Holiday Inn & Estados Unidos & 1992 & Turismo \\
\hline \multirow[t]{5}{*}{ Situr } & Diamond Resorts & Canadá & 1992 & Inmobiliario \\
\hline & Club Robinson & Alemania & 1992 & Turismo \\
\hline & Caribean Villas & R. Dominicana & 1992 & Turismo \\
\hline & Bel-Air & Estados Unidos & 1992 & Turismo \\
\hline & Thomas Cook & Reino Unido & 1993 & Turismo \\
\hline Sidek & Trafalgar House & Reino Unido & 1992 & Construcción \\
\hline Gmd & Benito Roggio & Argentina & 1993 & Construcción \\
\hline Elektra & Western Union & Estados Unidos & 1994 & Servicios \\
\hline Tv azteca & $\mathrm{NBC}$ & Estados Unidos & 1994 & TV programación \\
\hline \multirow[t]{3}{*}{$\mathrm{Bi}$} & Underwater Inv. & Estados Unidos & 1994 & Petróleo \\
\hline & Lyonnaise Eaux & Francia & & Tratamiento de agua \\
\hline & Kellog ${ }^{a}$ & Estados Unidos & 1989 & Construcción \\
\hline lusacell & Bell Atlantic & Estados Unidos & 1993 & Telecomunicaciones \\
\hline \multirow[t]{2}{*}{ Herdez } & Gilroy Foods & & 1992 & Transporte \\
\hline & Heinz & Estados Unidos & 1994 & Alimentos \\
\hline Geupec & Pepsico & Estados Unidos & 1992 & Bebidas \\
\hline \multirow[t]{4}{*}{ San Luis } & Triangle Springs & Estados Unidos & 1993 & Repuestos autom, \\
\hline & Cambior & Canadá & 1993 & Minería \\
\hline & Teck & Canadá & 1993 & Minería \\
\hline & Hillsborough & Canadá & 1993 & Minería \\
\hline \multicolumn{5}{|l|}{$\begin{array}{l}\text { Ramnnat: } \\
\text { Banacci }\end{array}$} \\
\hline \multirow{3}{*}{ Accival } & Swiss Bank Corp. & Suiza & 1993 & Corretajes \\
\hline & $\mathrm{MCI}$ & & 1995 & Telecomunicaciones \\
\hline & Aegon NV & NVS & 1995 & Seguros \\
\hline GFB & GTE & & & Telecomunicaciones \\
\hline GSERFIN & GE & Estados Unidos & 1992 & Leasing \\
\hline
\end{tabular}

Fuentes: Jurgensen (1993), América Economía (1993-1994), Memorias anuales y circulares de ofertas de empresas; revistas en bibliografía.

a Alianza que permitió a grupos mexicanos expandir sus operaciones a mercados internacionales,

${ }^{b}$ Esta alianza abortó en diciembre de 1993. 
Entre los más importantes destacan Vitro-Corning, Cifra-Walmart y Modelo-Anheuser Busch.

A pesar de su fracaso transcurridos dos años, la alianza Vitro-Corning podría considerarse un paradigma por diversos motivos: fue concebida en términos más igualitarios, se transformó rápidamente en un ejemplo que otros empresarios mexicanos trataban de emular y significó un proceso gradual de negociaciones que duró meses y que fue precedido por una interacción intensa y contactos previos más tradicionales.

Un análisis más de cerca de sus características muestra que, a diferencia de los tradicionales joint ventures del decenio de 1970, que generalmente daban acceso o facilitaban la entrada de una empresa transnacional al mercado mexicano, la alianza Vitro-Corning fue un joint venture doble. Ambas compañías intercambiaron activos en sus inversiones en la industria del vidrio para el consumo. Aparte mejorar la posición de Vitro en el mercado de los Estados Unidos, la alianza era complementaria en otros aspectos. No había mucha sobreposición de productos similares, lo que permitía segmentar los mercados de acuerdo con los niveles de ingreso y preferencias de los consumidores. La combinación de las redes de distribución y conocimientos de comercialización se suponía de beneficio para ambas partes. Ninguna de estas empresas había desarrollado sistemas de distribución internacional debido a las barreras comerciales prevalecientes hasta el decenio de 1990. Por último, pero también importante, se acordó el intercambio de directores y ejecutivos de alto nivel.

Aunque Vitro ha participado al menos en otras dos alianzas estratégicas con el concepto de doble joint venture, y en nueve joint ventures de corte tradicional, el fracaso de la alianza estratégica Vitro-Corning muestra algunas de las grandes dificultades de tratar de acceder a la red de empresas globales. Según los ejecutivos de Corning, la separación se debió a distintas filosofías de administración de la empresa (Business Mexico, 1994). Pero Adrián Sada G., Presidente del Directorio de Vitro en ese entonces, atribuyó el fracaso al hecho de que "el TLC no favorece a los fabricantes mexicanos de productos de vidrio para la mesa y la cocina" (Vitro, 1993; p. 4). La alianza entonces se redefinió para cubrir solamente aspectos de comercialización.

Bleeke y Ernst (1991, p. 129) prevén problemas en alianzas estratégicas entre empresas de tamaño y fuerza muy distintas:

Cuando un socio es débil, administrar la alianza parece ser una distracción demasiado grande del objetivo de introducir mejoras en otras partes del negocio. Cuando las sociedades no equilibradas tienen éxito suele deberse a que el socio fuerte aporta la capacidad crucial para el éxito de la sociedad; arrastra tras de sí por un tiempo al socio más débil antes de absorberlo o encontrar otro socio.

Aún siendo importante que los socios tengan capacidades o habilidades complementarias, el equilibrio de fuerzas es también importante, sobre todo en las sociedades en que uno aporta el producto y el otro el mercado. Cuando un socio aporte el producto y la tecnología y el otro el acceso al mercado apetecido, a menudo hay una gran dosis de suspicacia por ambas partes. Cada socio teme que el otro usurpe la ventaja de su propiedad.

La suerte de las alianzas Vitro-Corning y CifraWal-Mart parecen confirmar esta opinión. El primero de estos casos ha sido ya analizado. En el último, el socio más fuerte (Wal-Mart) se apoderó del socio más débil seis años después de haber comenzado la alianza. En 1991, Cifra, el vendedor minorista más grande de México, hizo equipo con Wal-Mart, el minorista más grande de los Estados Unidos. La unión abarcaba diversos proyectos en ambos países (entrevista 5). En 1997, los socios mexicanos acordaron vender su participación mayoritaria con el argumento de problemas en el traspaso generacional de la familia.

Modelo y Anheuser-Busch, cerveceros líderes en México y los Estados Unidos, respectivamente, juntaron fuerzas en abril de 1993. La unión incluía cuatro áreas: i) Adquisición por Anheuser-Busch de un 17 por ciento del capital accionario de Modelo, con opción de adquirir hasta el 30 por ciento; ii) Modelo seguiría siendo importador y distribuidor exclusivo de Budweiscr y otras marcas de la cervecería estadounidense; iii) Anheuser-Busch nombraba a tres directores en el directorio de Modelo y un representante de Modelo se integraba al directorio de Anheuser-Busch; y iv) intercambio de personal ejecutivo y de administración entre las empresas, especialmente en las áreas de comercialización, planificación y finanzas. ${ }^{9} \mathrm{El}$ futuro de esta alianza no está decidido, pero muchos temen que Anheuser finalmente asuma el control por la vía de la compra.

El cuadro 2 muestra la cantidad creciente de asociaciones que han formado los grupos mexicanos, cada una de las cuales puede corresponder a distintos tipos

\footnotetext{
${ }^{9}$ Véase Business Mexico (1993, p. 64) y Latín American Newsletters (1993).
} 
de acuerdos. No obstante, los casos analizados con mayor detalle muestran la naturaleza de la red global. Las alianzas estratégicas juntan a dos o más empresas globales en una red empresarial. Es posible que cada una cumpla una función distinta. Algunas organizaciones pueden tomar posiciones centrales, en tanto que otras permanecen en un plano marginal, en particular respecto de la toma de decisiones que afectan la arti- culación y la dinámica de la red. De esta forma, la colaboración y la integración de las múltiples y muy diferenciadas funciones operan sólo después de un complejo proceso de negociación normado por un marco institucional global. No todos los agentes participan de la misma forma en la formulación de las normas globales que diseñan y restringen las opciones estratégicas.

IV

\section{Expansión a los mercados financieros internacionales}

En el decenio de 1980, la mayor parte de las empresas latinoamericanas no podía participar en los mercados financieros internacionales, salvo para renegociar deudas, convertir deudas en aportes de capital y, posteriormente, para recomprar sus propios títulos de deuda a determinadas tasas de descuento. Sin embargo, todas estas negociaciones implicaban un proceso de aprendizaje sobre cómo maniobrar en los circuitos financierós mundiales, abriendo el camino a operaciones más agresivas y sofisticadas en el decenio de 1990.

Sin embargo, antes de que los grupos pudieran emprender negociaciones, debían ser afianzados por el gobierno mexicano. El gobierno, mediante un mecanismo muy complejo - Ficorca-, ${ }^{10}$ respaldaba la deuda externa privada." La mayoría de los grandes grupos - especialmente los de Monterrey— habrían caído en la morosidad si no es por la intervención del gobierno. ${ }^{12}$ En la segunda mitad del decenio se ofreció a las empresas privadas la oportunidad de adquirir títulos de deuda pública con atractivos descuentos. En abril de 1987, el gobierno mexicano autorizó a los inversionistas privados mexicanos para comprar en el

\footnotetext{
${ }^{10}$ El fideicomiso - Ficorca- - fue un mecanismo para que, una vez alcanzado un acuerdo con instituciones de crédito extranjeras para definir las condiciones de pago, las empresas inscritas en el programa tuvieran derecho a adquirir las divisas necesarias para el pago del capital y los intereses con tipos de cambio fijos subvencionados. El programa Ficorca ofrecía distintas opciones para la compra de divisas destinadas a pago de intereses y capital.

11 Garrido y Quintana (1987) cualificaron la transferencia total de fondos del Ficorca a grupos privados,

12 Alfa y Moctezuma, de hecho estuvieron en mora por un atraso excesivo en llegar a acuerdo con sus acreedores. Al comenzar las negociaciones, los acreedores de Alfa eran 170, lo que hizo que el proceso fuera muy lento.
}

mercado secundario deuda pública para prepagar su propia deuda externa. La deuda externa mexicana fue adquirida en 50 a 60 por ciento de su valor y fue recomprada por el gobierno en pesos en cerca de! $90 \%$ de su valor. Si se usaba para prepagar deuda en Ficorca se tomaba a su valor nominal (100 por ciento). Algunos grupos sacaron pingües ganancias de esta situación y otras innovaciones de reducción de deuda.

La apertura de la economía mexicana al exterior y, luego, las negociaciones para formar el NAFTA, obligaron a muchas empresas a fortalecer su posición. Para ser capaces de defender sus mercados en México, tenían que crecer, ser más competitivas, más eficientes y más productivas. Una nueva ola de fusiones, reordenamientos e inversión en las nuevas tecnologías para reducir costos significaron también reorganizaciones de la estructura de capital y un mayor acceso a los mercados internacionales de valores. Esto, con el tiempo, dio una mayor familiaridad con los estándares internacionales de presentación, contabilidad e información.

Las primeras incursiones en los mercados internacionales de valores entre 1989 y comienzos de 1992, tuvieron por objetivo los mercados accionarios. Desde abril a junio de 1992, según algunos analistas, la mayor parte de las emisiones de acciones que circulaban en los mercados internacionales en forma de ADR y GDR ${ }^{13}$ (American Depository Receipts y Global Depo-

\footnotetext{
13 ADR y GDR son certificados que circulan en los mercados bursátiles internacionales que representan el patrimonio accionario de una empresa. Las acciones se depositan en una institución neutral, habitualmente Nafinsa, que emite certificados que representan esa masa accionaria. El titular de un certificado tiene derecho a dividendos, pero no tiene derecho a voto en las asambleas de accionis-
} tas. 
sitory Receipts) se fue a pique por saturación del mercado. Pero a fines de 1992 se utilizaba ya una gran variedad de complejos instrumentos accionarios y de deuda. La participación en ferias internacionales y presentaciones a analistas de mercado y administradores de fondos se convirtieron en parte de una nueva función de promoción y planificación financiera. Se crearon equipos de administración especializada de promoción financiera en las estructuras empresariales.

El cuadro 3 muestra que entre 1989 y 1992, más de 35 empresas mexicanas entraron al mercado accionario con ADR o GDR. Sólo 20 de estas compañías estaban plenamente registradas en la Comisión de Bolsa y Valores de los Estados Unidos. ${ }^{14}$ Los restantes comercian fuera de la bolsa en los mercados institucionales (cajas de pensiones y seguros), donde están protegidos de compras hostiles, adquisiciones apalancadas y otras estrategias agresivas de inversión (Mac Kee, ed., 1989).

Diversos grupos mexicanos (Fetnsa, Vitro e ICA) utilizaron ADR y GDR para financiar adquisiciones o programas de inversión; otros grupos los usaron para reorganizar intereses de propiedad; durante el proceso de reprivatización de los bancos, los créditos puente fueron pagados parcialmente con el producto de ofertas secundarias o primarias (de ADR y GDR); y el gobierno usó también este mecanismo para complementar el programa de privatización de Telmex (Salas-Porras, 1997).

La mayor parte de la expansión a mercados internacionales, ya por adquisiciones, joint ventures o alianzas estratégicas, ha sido llevada a cabo con escasa o ninguna inversión. Hubo que idear operaciones financieras muy sofisticadas, incluida la reconversión de deudas a precios fuertemente castigados, para reordenar

\footnotetext{
${ }^{14}$ Sólo las compañías registradas pueden operar directamente en la Bolsa de Valores de Nueva York. No todos los grupos mexicanos cumplen los requisitos de información de la Comisión de Bolsa y Valores de los Estados Unidos en cuanto, por ejemplo, al número y frecuencia de informes, historia de operaciones en los últimos cinco años, y destino del producto de la emisión de nuevas acciones o títulos. Las compañías registradas en la Bolsa de Nueva York están sujetas a normas más rigurosas para asegurar un menor riesgo a los inversionistas individuales que no pueden operar con valores fuera de bolsa. Por ello, las empresas con registro pleno tienen acceso a fondos de inversionistas individuales que le dan a los mercados institucionales mayores posibilidades de comercialización. Sólo los inversionistas institucionales pueden operar en el mercado de valores fuera de bolsa, el que tiene menor liquidez. Las transacciones de mercado fuera de bolsa se realizan a través de una red telefónica y computacional que une a los corredores (casas de corredores o bancos de inversión) que negocian acciones y bonos fuera de una bolsa organizada.(Downes y Goodman, 1995).
}

los intereses de propiedad a nivel internacional. ${ }^{15} \mathrm{Y}$ algunas empresas mexicanas gozaban de una posición favorable por diversas razones: i) el NAFTA había cambiado radicalmente la percepción de riesgo respecto de México; ii) los inversionistas internacionales comenzaron a interesarse por los títulos latinoamericanos porque ofrecían en promedio rentabilidades superiores; iii) la mayoría de los grupos mexicanos que operaban en los mercados internacionales lograron bajos índices de endeudamiento con relación ai capital el decenio de 1980; y iv) algunos grupos tenían un gran potencial de liquidez.

En 1993, muchos analistas e inversionistas consideraban a México en términos más favorables que al resto de América Latina. La excelente acogida de todas las emisiones de deuda lanzadas entre 1992 y 1993 confirma esta apreciación. La mayor paite de las emisiones que se muestran en el cuadro 4 debieron aumentar la oferta inicial, fueron suscritas con creces y valuadas a tasas relativamente bajas considerando las condiciones de mercado para los países de alto riesgo, Sin duda, la más grande y reciente emisión fue la de Cemex, en mayo de 1993, La demanda fue tan alta que la oferta inicial tuvo que ser aumentada de seiscientos a mil millones de dólares. Esta y otras emisiones lanzadas en 1991 y 1992 (véase el cuadro 4) lograron cubrir las necesidades financieras derivadas de sus recientes adquisiciones en México (Empresas Tolteca, en 1989 y Cernentos Hidalgo, en 1993) y en España (La Valenciana y Sansón, en 1992) y los nuevos proyectos de inversión citados anteriormente. ${ }^{16}$ Cemex no habría sido capaz de comprometerse en estas multimillonadas transacciones internacionales si su apalancamiento hubiese sido alto y su potencial de autofinanciamiento bajo, Sin embargo, también lo cierto era lo contrario. A pesar de todas las emisiones de títulos de deuda en 1993, a fines de año su tasa de endeudamiento (coeficiente entre pasivos totales y activos totales) era sólo del 50 por ciento y la generación de fondos líquidos representaba el 30 por ciento de las ventas (cuociente entre fondos líquidos provenientes de ingresos netos y ventas netas).

\footnotetext{
15 Según Michalet (1991, pp. 43), el proceso de globalización es diferente del proceso multinacional, entre otras razones porque "...el rediseño de la industria mundial no está dando origen a un proceso de acumulación de capital. A diferencia del período previo, la inversión extranjera directa constituye principalmente un cambio en la propiedad y el control de compañías existentes."

16 Para la licitación española, JP Morgan negoció un préstamo de empalme de mil seiscientos millones de dólares con el Citibank.
} 
CUADRO 3

México: Emisiones de valores internacionales por empresas mexicanas

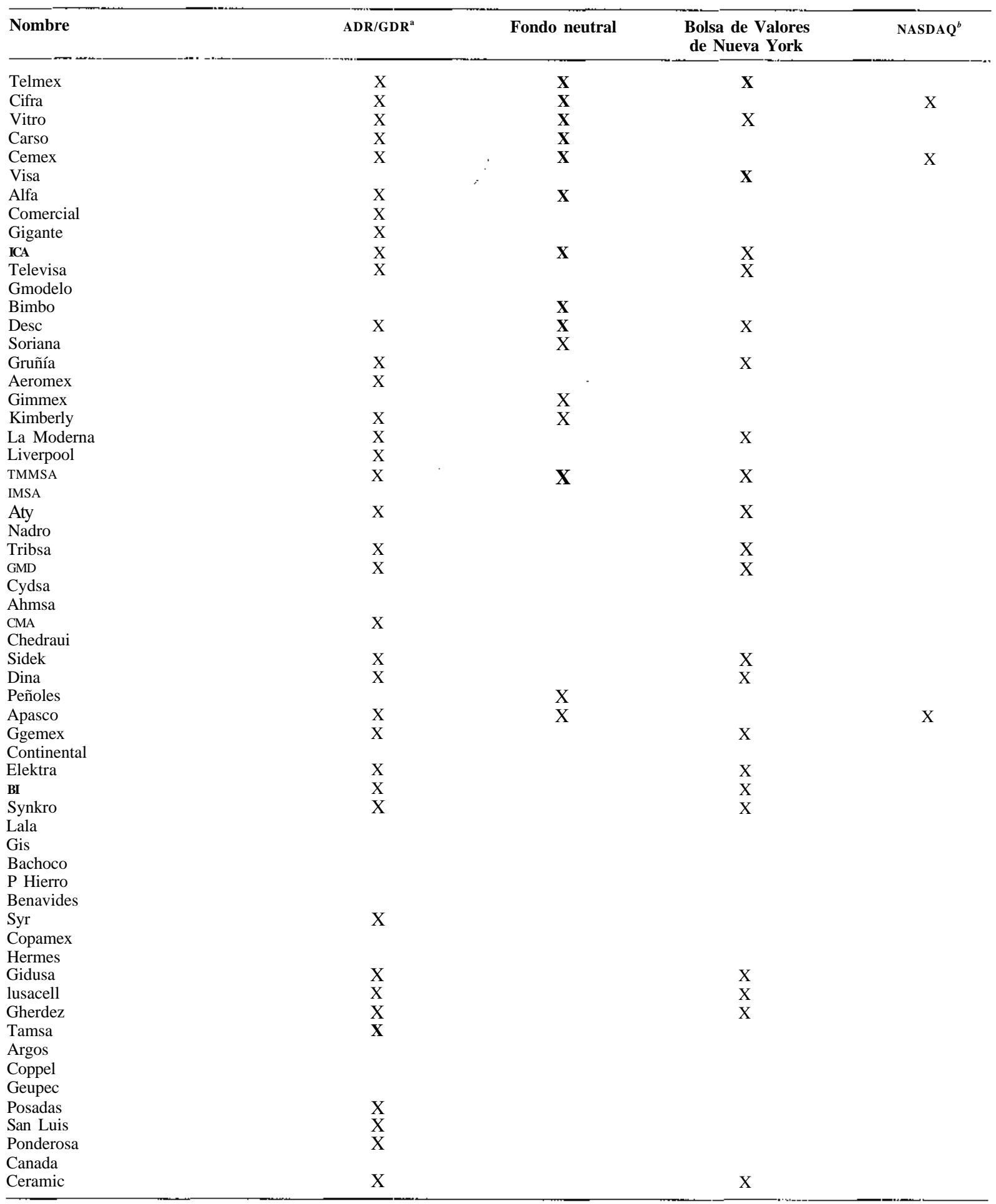

Fuentes: BMV/AMIB, (1995-1996); Banamex-Aceival, Semana Bursátil.

a ADR/GDR; American Depository Receipts y/o Global Depository Receipts.

h NASDAQ : National Association of Security Dealers Automated Quotation. 
CUADRO 4

México: Instrumentos de deuda para los mercados internacionales', de valores (Millones de dólares)

\begin{tabular}{lllll}
\hline Carso & ECP & Citicorp & \\
Ceinex & IiCP & 300 & & \\
Visa & & 425 & Lazard & 92 \\
Alfa & NCP & 100 & Citicorp & 92 \\
lea & Eurobond & 225 & Merril & 93 \\
Televisa & Enroñóte & 100 & Citicorp & 92 \\
Desc & ECP & 100 & Lehman & 92 \\
Gruma & Euronotes & 125 & Citicorp & 93 \\
Acroinex & Fixed rate notes & 100 & Chemical \\
Liverpool & ECP & 100 & Citicorp & 92 \\
Cydsa & Term note progr & 250 & & 92 \\
Apasco & Eurobond & 50 & JP Morgan \\
Iusacell & Eurobond (3 años) & 45 & & 92 \\
\hline
\end{tabular}

Fuente: International Financial Review (1992 y 1993).

${ }^{a}$ ECP: Eurolítulos comerciales.

La evolución desde la negociación y contratación de créditos privados con bancos e instituciones financieras a la emisión de diferentes y complejos instrumentos accionarios y de deuda como medio para obtener fondos externos, demoró diez años (de 1982 a 1992). Las relaciones múltiples y las contradicciones con numerosos agentes del mercado mundial de valores - agentes más importantes, inversionistas institucionales, banqueros de inversión, administradores de fondos, corredores, etc. - presionó a los grupos y los obligó a cambiar sus estructuras, costumbres y estrategias empresariales. Las prácticas de presentación, contabilidad e información se hicieron más abiertas. Algunos grupos reorganizaron su estructura por sectores para responder a las necesidades de algún fondo de pensiones que invertía con criterios sectoriales. La estrategia de corto plazo de la comunidad del mercado internacional obligó a los grupos mexicanos a presentar información y estados financieros trimestrales.

\section{V}

\section{Redes de distribución}

Este es quizás el aspecto en que las grandes empresas mexicanas han estado trabajando por más tiempo. A pesar de ello, no siempre han tenido buenos resultados en la construcción de sus propias redes. El éxito depende no sólo de la calidad de los productos, sino también de la capacidad de administración para coordinar tareas cada vez más complejas de producción, promoción, comercialización y distribución. Más aún, se necesitan equipos profesionales especializados para manejar los esquemas jurídicos e institucionales externos y transnacionalcs (acuerdos comerciales del Organismo Mundial del Comercio, del Tratado de Libre Comercio de América del Norte y otros).

Hasta el decenio de 1980, las exportaciones manufactureras dependían fundamentalmente de la situa- ción del mercado interno. Si la demanda se deprimía, los grupos buscaban canales para orientar sus excesos de producción. A partir de la segunda mitad del decenio de 1980, las estrategias de comercio exterior entre los grupos manufactureros se volvieron cada vez más agresivas. Una mayor parte de la capacidad productiva se orientó directamente a los mercados externos y una mayor interacción entre productores y consumidores - particularmente empresas transnacionales en los sectores automotriz y electrónico- llevó a los productores a expandir su red y luego a seguir a sus clientes a otros países.

Como puede apreciarse en el cuadro 5, varias empresas mexicanas aumentaron considerablemente la participación de sus exportaciones en sus ingresos to- 
tales. Muy pocos grupos, no obstante, articularon un sistema de distribución internacional que incluyera transporte (barcos, camiones, terminales, centros de distribución, etc), bodegas, comercialización, agentes de promoción y representantes legales. Entre las más importantes están Televisa, Cemex y Modelo. Desde la perspectiva del agente, las experiencias de Cemex y Modelo son particularmente esclarecedoras ya que debieron enfrentar a poderosos intereses que trataban de evitar su crecimiento en los mercados de los Estados Unidos y Europa. Para hacerlo, tuvieron que aprender desde las muy sofisticadas leyes antidumping y las normas del GATT hasta reglas menos formales y trucos comerciales.

En 1988, siete productores de cemento de Texas, Nuevo México, Florida y Arizona, comandados aparentemente por una filial de la empresa transnacional suiza Holderbank, se quejaron ante la Comisión Fede- ral de Comercio de los Estados Unidos de que los estaban afectando las importaciones de cemento de bajo precio provenientes de México. La Comisión impuso aranceles compensatorios que fluctuaban del 50 al 58 por ciento. Las exportaciones mexicanas de cemento a los Estados Unidos cayeron de 3.5 millones de toneladas a menos de un millón y Cemex salió muy perjudicada ya que le correspondía cerca del $90 \%$ de ese total. Fracasaron diversos intentos de anular la sentencia hasta que, en julio de 1992, un jurado internacional dictaminó que los Estados Unidos habían violado el código antidumping del GATT. LOS representantes comerciales de los Estados Unidos ofrecieron a México suspender la sanción si México retiraba la queja ante el GATT, mantenía sus exportaciones a los Estados Unidos dentro de ciertos límites y precios y abría su propio mercado a las importaciones de cemento. Las sanciones han sido reducidas gradualmente, aunque no han sido eliminadas (entrevista 2).

CUADRO 5

México: Exportaciones, redes de distribución y acuerdos comerciales de las empresas

\begin{tabular}{|c|c|c|}
\hline Grupo & Gastos/ventas 1993 & Redes comerciales $y$ mercados \\
\hline & $\mathrm{TO} \overline{\mathrm{TO}}$ & \\
\hline Telmex & 20.3 & \\
\hline Vilro & 22.0 & ICI America, Pilkington Bros. Acuerdo con GM \\
\hline Careo & 16.2 & \\
\hline Cemex & 11.5 & Sunbelt, Distribution Centres, Marine Terminals \\
\hline Visa & 2.7 & Representantes en los Estados Unidos \\
\hline Alfa & 21.4 & Eastman Chemical, acuerdo "just in time" con Ford \\
\hline lea & 6.8 & ICA Tech, ICA Construction, Tremec Trading Co. \\
\hline Televisa & 22.5 & Galavisión, sociedad europea \\
\hline Gmodelo & 8.8 & Moctezuma Imports, Gainbrinus \\
\hline Bimbo & 1.1 & Sara Lee \\
\hline Desc & $2 t .3$ & Chemtec, Housmex, acuerdos "just in time" con GM \\
\hline Gmexico & 55.4 & Minera México International, Western Copper Supplies \\
\hline Kimberly & 3.1 & Comercio mtercompañía con empresa matriz \\
\hline La Moderna & 20.0 & Medio y lejano oriente \\
\hline Ceianese & 32.3 & Comercio intercompañía con empresa matriz \\
\hline Tmmsa & 40.3 & The Texas-Mexican Railway Co., Cardiff, Marine \\
\hline Imsa & 12.2 & Representantes \\
\hline Tribasa & 1.0 & \\
\hline Cydsa & 26.1 & Rayon Yarn, Intermex, Jansen, Veratec (fibras) \\
\hline Ahmsa & 3.9 & \\
\hline $\mathrm{Cma}$ & 61.7 & Acuerdos con agentes de viajes \\
\hline Sidek & 3.3 & Pacific Steel Inc., acuerdos con agentes de viajes \\
\hline Dina & 30.8 & Acuerdo con M. Benz \\
\hline Peñoles & 41.0 & General Products Co., Pañoles y Chemicals \\
\hline $\mathrm{Bi}$ & 13.0 & Acuerdo con Kellog y representantes en los EE.UU. \\
\hline Synkro & 66.0 & Filiales en EE.UU. y representantes en A.Latina \\
\hline Gis & 15.4 & Representantes \\
\hline Bachoco & 20.4 & \\
\hline Herclez & 3.0 & Festin Food \\
\hline Tamsa & 71.4 & ITL, TAMSA Inc. Tamtrade \\
\hline Argos & 8.4 & \\
\hline Posadas & 12.1 & \\
\hline San Luis & 74.5 & Acuerdos de mercado \\
\hline
\end{tabular}

Fuentes: Expansión (1994); BMV (1994) 
La proximidad geográfica de Cemex con los Estados Unidos representaba una ventaja competitiva - particularmente al considerar los costos de transporte- lo que sin duda era un problema para los patrocinantes de la demanda legal (la transnacional suiza Holderbank y la francesa Lafargue, la más grande y la segunda del mercado, respectivamente). En el transcurso de la disputa legal, que duró más de dos años y que todavía no termina totalmente, Cemex se ha visto obligada a encontrar nuevos mercados en Japón, Singapur, y otros países del Sudeste Asiático, Europa y América Latina, diversificando su red de representantes comerciales y agentes.

En el caso de Modelo se destacan las nuevas estrategias que han debido poner en práctica las empresas mexicanas para expandirse a los mercados del mundo desarrollado. Entre 1986 y 1987, la marca Corona Extra, de Modelo, llegó a ser la segunda cerveza importada de mayor venta en los Estados Unidos.
Esta marca mexicana desplazó a Heineken del primer lugar en California, Texas y Colorado. Muy pronto después de que Corona era reconocida como la segunda mejor cerveza importada, comenzó a correr en todo el país el persistente rumor de que la cerveza estaba contaminada. Este rumor afectó algunos mercados regionales claves. Después de intentar otras estrategias, el representante de Modelo en los Estados Unidos presentó una demanda por tres millones de dólares contra Luce \& Sons, Inc., el distribuidor de Heineken responsable de difundir el rumor. La disputa se solucionó cuando Luce acordó manifestar públicamente que Corona no estaba contaminada. Entre 1986 y 1987 Corona aumento su participación en el mercado de cerveza importada de los Estados Unidos, del II al 18 por ciento (contra Heineken, que bajó del 29.3 al 25 por ciento). Modelo representaba en 1992 el 69 por ciento de todas las exportaciones de cerveza de México, con ventas en 59 países. $^{17}$

\section{VI}

\section{Estrategias globales}

En los casos examinados en este artículo hay un esfuerzo deliberado de las empresas por adoptar estrategias globales para convertirse en empresas transnacionales. En términos generales, esta estrategia se considera necesaria para superar, o al menos mitigar, la ineficiencia, la falta de competitividad y la escasez crónica de recursos que caracteriza a las economías cerradas, protegidas y subdesarrolladas. Al menos cuatro de los entrevistados (2, 3, 4 y 8, representantes de Cemex, Carso, Alfa y Vitro, respectivamente) relacionaron explícitamente la competitividad y la posibilidad de defensa de sus mercados (nacional y sectorial) a la adopción de estrategias globales. Según la administración de Vitro, por ejemplo, "A medida que la economía mexicana se abría, la única alternativa consistía en la expansión a los mercados externos y, simultáneamente, proteger los mercados nacionales, pero sobre la base de las reglas del juego de ios mercados internacionales." (entrevista 8 ).

El esfuerzo de internacionalización es entonces la estrategia para sobrevivir y superar algunas limitaciones y restricciones tradicionales que caracterizan a la burguesía nacional, particularmente, su ineficiencia y su gran dependencia del Estado. Para ser internacionales, los empresarios mexicanos tuvieron que adoptar una posición más activa, agresiva, consciente y autoanalítica. La orientación estratégica presupone que este sector de la burguesía nacional se distancie del papel que ha estado desempeñando en la economía, lo examine críticamente y procure transformarlo.

Mis entrevistas demuestran que esta planificación estratégica-distintas medidas conectadas lógicamente para lograr un resultado específico- está hoy profundamente arraigada en las prácticas empresariales. Las estrategias globales - conjuntos de medidas deliberadas para ganar o mantener una posición en el mercado mundial'- han transformado la orientación predominantemente introvertida de las metapreferencias empresariales en una orientación predominantemente extraveitida.

La estrategias internacionales formuladas y puestas en marcha por los grupos mexicanos son bastante completas. Incluyen diferentes combinaciones de las

\footnotetext{
17 Véanse Wall Street Journal 1987'; Journal of Commerce, 1988 y Latin American Newsletters, 1993.
} 
recetas de reestructuración ${ }^{18}$ diseñadas por las empresas multinacionales de los países desarrollados en el decenio de 1980; las nuevas formas de crecimiento por adquisición (privatizaciones, compras hostiles, adquisiciones apalancadas y adquisiciones por el personal de las empresas); posicionamiento o comparación con normas de excelencia internacionales; alianzas estratégicas y creación de redes; la utilización de nuevos instrumentos financieros (títulos comerciales, Eurobonos, opciones de compra y otros dispositivos financieros).

Las operaciones a escala internacional expanden el campo de acción no sólo porque la gerencia debe coordinar actividades en diferentes países, sino particularmente porque la competitividad y el desempeño deben ser evaluados en una escala internacional, es decir, en comparación con los resultados de competidores mundiales. Este nuevo énfasis en el posicionamiento influye sobre todo su crecimiento y sus estrategias de reestructuración. El posicionamiento en escala mundial se transforma así en uno de los objetivos principales en casi todas las áreas de la acción empresarial.

Las presentaciones a agentes de la comunidad del mercado global ${ }^{19}$ dan invariablemente gran importancia al posicionamiento en varios renglones (ingreso neto, productividad, rentabilidad de los activos, etc). Las memorias, las circuíales de ofertas, las ferias internacionales, las presentaciones y otros instrumentos de promoción financiera no pueden dejar de tocar el problema. La mayor parte de mis entrevistas muestra que el posicionamiento ha transformado a fondo la lógica de la administración estratégica en las empresas mexicanas. Una de las consideraciones más importantes que tuvo Cemex para comprar Sansón y La Valenciana en España, fue que el grupo lograría una rentabilidad sobre sus activos mayor que la de sus competidores en Europa (entrevista 2). Lorenzo Zambrano, ejecutivo máximo de Cemex, considera que para competir con empresas transnacionales de países industrializados, la gerencia mexicana debe conocerlas detalladamente,

\footnotetext{
18 Por estrategias de reestructuración yo entiendo una extensa organización empresarial que actúa en todos los niveles, financiero, tecnológico, organizational, etc. Estas estrategias se formularon por primera vez en el decenio de 1970, pero las distintas medidas financieras y empresariales han cambiado bastante desde entonces. Entre los nuevos elementos de importancia encontramos las adquisiciones apalancadas, los bonos chatarra (de alto riesgo) para financiar adquisiciones, alianzas estratégicas y demás. Véase Bibeault (1982) y Slatter (1984).

19 Por comunidad del mercado mundial, entiendo a todos los agentes involucrados en la compra y venta de valores en los mercados
} transnacionales. entender sus estrategias, seguir su desarrollo en los distintos países, identificar sus áreas vulnerables y prever sus próximas movidas (IMEF, 1993; p. 10).

Las empresas no adoptan necesariamente todos los componentes de la fórmula internacional porque su situación específica o sectorial puede responder a problemas y restricciones diferentes. Las posibles combinaciones de estrategias son así múltiples. Dependen de la situación financiera de la empresa y de las características de su negocio principal, estructura de costos, estrategia histórica, etc.

Antes de la apertura, los negocios de la mayoría de las grandes empresas mexicanas podían considerarse estancados. Es decir, se trataba de firmas con activos subutilizados y administración ineficiente, según estándares transnacionales. Bajo condiciones de mercado cerrado y protegido, esas empresas sobrevivían a pesar de su pobre desempeño. Al abrirse la economía, tuvieron que adaptarse al medio ambiente de producción internacional, si querían tener éxito. Entre las estrategias más frecuentes adoptadas para superar la debilidad competitiva, se pueden citar las prescritas por los especialistas de la reestructuración clásica (Bibeault, 1982 y Slatter, 1984): i) reorientación desde el producto al mercado: adoptada por Alfa, Desc, San Luis y, en menor medida, VISA; ii) reducción de costos: adoptada en particular por Alfa, Cemex, Carso, Vitro; iii) mejoras en la comercialización: Bancomer, Modelo; iv) reducción de activos: Alfa, Cemex, Carso; v) profesionalización de los cargos ejecutivos superiores y directorios: Alfa, Carso, visa-Bancomer.

Las recetas de reestructuración se difundieron rápidamente en el medio empresarial convirtiéndose en tema obligado entre los altos ejecutivos. Surgieron los especialistas o 'artistas' de la reestructuración, auspiciados y guiados por agentes transnacionales, consultores y bancos de inversión a medida que las restricciones internas y externas (ambientales y de administración) creaban una situación de reestructuración para la mayoría de las empresas mexicanas. ${ }^{20}$ Las expectativas de éxito se relacionan estrechamente con el desarrollo previo y el apoyo de otros agentes que puedan beneficiarse del proceso.

\footnotetext{
${ }^{20}$ Hay controversia respecto del papel que desempeñaron esos agentes en el proceso de reestructuración empresarial en los Estados Unidos y en otros países. Algunos autores (Vedder, 1989, p. 14) sostienen que contribuyeron a hacer más eficientes y productivas las empresas; otros (Bruning, 1989, p.53; Brock y Adams, 1989, pp. 34-35), piensan que fomentaron la especulación, destruyeron capacidad productiva y cortaron empleos.
} 
Carso, como Kohlberg, Kravis, Roberts y Fortsman Little, en los Estados Unidos (Useem, 1993, p. 318), y Trafalgar House Ltd., en Inglaterra (Bibeault, 1982, p. 87), se ha especializado en la privatización y compra de grandes empresas que enfrentan dificultades de distintos tipos. La privatización de empresas estatales dio origen a un gran número de reestructuraciones porque habitualmente estaban mal administradas. Carso fue uno de los grupos que mejor aprovechó esta coyuntura. El grupo ha tenido bastante éxito en la reestructuración

\section{VII \\ Conclusiones}

Efectos combinados de factores nacionales e internacionales contribuyeron decisivamente entre 1982 y principios del decenio de 1990 para promoverla internacionalización de empresas mexicanas. Los factores nacionales más importantes fueron: i) la recesión de los años ochenta que obligó a los grupos a buscar y abrir nuevos mercados para sus productos; ii) la negociación de la deuda externa, Ficorca y la depreciación de la deuda mexicana que las enganchó con nuevos circuitos y agentes financieros, más sofisticados y modernos; iii) la apertura de la economía, su afiliación al GATT y al NAFTA, que se tradujo en menor protección, menos subsidios y menos transferencias; iv) la re valuación de las empresas mexicanas a la luz de las expectativas generadas por el NAFTA; V) las proyecciones de la deu$\mathrm{da}$, que crearon oportunidades financieras.

Entre los factores internacionales más importantes, se pueden citar: la internacionalización de un número creciente de sectores industriales, asociaciones y redes, lo que abre nuevos espacios y nichos para las empresas transnacionales de países en desarrollo; muchas empresas transnacionales de países capitalistas avanzados desplazan la atención de las actividades tradicionales a otras de vanguardia; el desarrollo tecnológico en la informática y las comunicaciones, que hace posible una compleja combinación de operaciones productivas, financieras y de comercialización; agentes financieros que buscan y crean opciones de inversión más atractivas (especulativas) en los mercados emergentes, en un ambiente de baja de las tasas de interés;

\footnotetext{
21 Está planeando una estrategia similar para Cementos Samper y Diamante, dos compañías colombianas adquiridas en mayo de 1996.
}

de esas firmas enclenques mediante una combinación de elementos - estrategias de administración más enérgica, instrumentos financieros, reducción de costos y reasignación de activos - que a menudo se utilizan para estos propósitos. Otro especialista exitoso de la reestructuración es Lorenzo Zambrano, presidente y gerente general de Cemex, que ha reestructurado Empresas Tolteca y aplicado una estrategia similar de reducción de costos y activos en las empresas españolas Sansón y La Valenciana recientemente adquiridas. ${ }^{21}$

y un marco normativo mundial más preocupado de los estándares ambientales y de calidad. ${ }^{22}$

Como puede apreciarse en el cuadro 6 , de los 60 grupos no financieros más grandes de México, 37 (esto es, casi el $60 \%$ ) se han transformado en empresas transnacionales, según la definición propuesta al principio de este artículo, es decir, desarrollan por lo menos dos tipos de actividades en los mercados internacionales (véase la introducción).

La solución más común es la de alianzas estratégicas. Un estudio riguroso de la bibliografía comercial revela que 29 de los 60 grupos no financieros más grandes de México han formado alianzas estratégicas en los últimos cinco años. Pero en contados casos esas alianzas permiten a los grupos mexicanos expandir sus operaciones a los mercados mundiales, ya sea facilitando las exportaciones o en actividades que agregan valor.

La expansión a los mercados de valores es una estrategia muy difundida ya que los contratos de crédito están gradualmente desapareciendo y el mercado de capitales mexicano es incapaz de satisfacer las necesidades de capital de estos grandes grupos. De cualquier forma, no todas las empresas mexicanas tienen la capacidad de organización para cotizar en los mercados internacionales de valores, particularmente en la bolsa de valores de Nueva York. De las 60 empresas minoristas industriales más grandes, 55 están inscritas

\footnotetext{
22 Aunque estos problemas escapan al propósito de este artículo, hay una gran discusión a este respecto como resultado de la expansión de jas maquilas, la apertura de la economía y las negociaciones del NAFTA.
} 
CUADRO 6

México: Trayectorias al mundo internacional de empresas mexicanas

\begin{tabular}{|c|c|c|c|c|c|}
\hline Grupo & Sector $^{a}$ & Filiales & Valores $^{11}$ & $\begin{array}{c}\text { Alianza } \\
\text { estratégica }\end{array}$ & Exportación \\
\hline Telmex & Comunicaciones & & $X$ & $\mathbf{X}$ & $\mathbf{X}$ \\
\hline Cifra & Dist. minorista & & $\mathrm{X}$ & $\mathbf{X}$ & \\
\hline Vitro & Vidrio & $\mathrm{X}$ & $\mathrm{X}$ & $\mathbf{X}$ & $\mathbf{X}$ \\
\hline Carso & Muy diversificado & $\mathrm{X}$ & $X$ & $X$ & $\mathbf{X}$ \\
\hline Cemex & Cemento & $\mathrm{X}$ & $\mathrm{X}$ & $\mathrm{X}$ & $\mathrm{X}$ \\
\hline Visa & Cerveza, bebidas & $\mathrm{X}$ & $\mathrm{X}$ & $X$ & $\mathrm{X}$ \\
\hline Alfa & Acero, petroquímica & & $\mathrm{X}$ & $X$ & $\mathrm{X}$ \\
\hline Comercial & Dist. minorista & & $\mathbf{X}$ & $\mathrm{X}$ & \\
\hline Gigante & Dist. minorisla & & $\mathbf{X}$ & $\mathrm{X}$ & \\
\hline lea & Construcción & $\mathrm{X}$ & $\mathbf{X}$ & $\mathrm{X}$ & $\mathrm{X}$ \\
\hline Televisa & Televisión & $\mathbf{X}$ & $\mathbf{X}$ & $\mathrm{X}$ & $\mathbf{X}$ \\
\hline Gmodelo & Cerveza & & $\mathbf{X}$ & $\mathrm{X}$ & $\mathbf{X}$ \\
\hline Bimbo & Alimentos & $\mathbf{X}$ & & $\mathrm{X}$ & $\mathbf{X}$ \\
\hline Desc & Muy diversificado & & $\mathbf{X}$ & $\mathrm{X}$ & $\mathbf{X}$ \\
\hline Soriana & Disl. minorista & & & & \\
\hline Gruma & Alimentos & $\mathbf{X}$ & $\mathbf{X}$ & & \\
\hline Aeromex & Aerolínea & & $\mathbf{X}$ & & \\
\hline Gmexico & Minería & & & & $\mathbf{X}$ \\
\hline Kimberly & Papel & & $\mathbf{X}$ & & $\mathbf{X}$ \\
\hline La Moderna & Tabaco & $\mathbf{X}$ & & & $\mathbf{X}$ \\
\hline Liverpool & Dist. minorista & & $\mathbf{X}$ & $\mathrm{X}$ & \\
\hline Tmmsa & Transporte & & $\mathbf{X}$ & $\mathrm{X}$ & $\mathbf{X}$ \\
\hline Uasa & Repuestos automov, & $\mathbf{X}$ & & $\mathrm{X}$ & $\mathbf{X}$ \\
\hline Aty & Dist. minorista & & $\mathbf{X}$ & $\mathbf{X}$ & \\
\hline Nadro & Petroquímica & & & & \\
\hline Tribasa & Construcción & & $\mathbf{X}$ & & $\mathbf{X}$ \\
\hline Gmd & Construcción & & $\mathbf{X}$ & $\mathbf{X}$ & \\
\hline Cydsa & Petroquímica & & $\mathbf{X}$ & $\mathbf{X}$ & $\mathbf{X}$ \\
\hline Ahmsa & Acero & & $\mathbf{X}$ & $\mathbf{X}$ & $\mathbf{X}$ \\
\hline Cma & Aerolínea & & $\mathbf{X}$ & & $\mathbf{X}$ \\
\hline Chedraui & Dist. minorisla & & & & \\
\hline Sidek & Acero, turismo & & $\mathbf{X}$ & $\mathbf{X}$ & $\mathbf{X}$ \\
\hline Dina & Automóviles & $\mathbf{X}$ & $\mathbf{X}$ & & $\mathbf{X}$ \\
\hline Peñoles & Minería & & & & $\mathrm{X}$ \\
\hline Apasco & Cemento & & $\mathbf{X}$ & & \\
\hline Ggemex & Bebidas & & $\mathbf{X}$ & $\mathbf{X}$ & \\
\hline Elektra & Dist. minorista, televisión & & & $\mathbf{X}$ & $\mathrm{X}$ \\
\hline $\mathrm{Bl}$ & Construcción & & $\mathbf{X}$ & $\mathbf{X}$ & $\mathbf{X}$ \\
\hline Synkro & Textiles & $\mathrm{X}$ & $\mathbf{X}$ & & \\
\hline Lala & Alimentos & & & & $\mathbf{X}$ \\
\hline Gis & Repuestos automov. & & & & $\mathbf{X}$ \\
\hline Bachoco & Agroindustria & & & & \\
\hline P Hierro & Dist, minorista & & & & \\
\hline Benavides & Dist. minorista & & & & \\
\hline Syr & Dist. minorista & & & & \\
\hline \multicolumn{6}{|l|}{ Copamex } \\
\hline Hermes & Metales & & & & $\mathbf{X}$ \\
\hline Gidusa & Productos de madera & & & & \\
\hline lusaceli & Comunicaciones & $\mathrm{X}$ & $\mathbf{X}$ & $\mathbf{X}$ & \\
\hline Herdez & Alimentos & $\mathbf{X}$ & & $\mathrm{X}$ & $\mathbf{X}$ \\
\hline Tamsa & Tubos de acero & & $\mathbf{X}$ & & $\mathbf{X}$ \\
\hline Argos & Bebidas & & & & $\mathbf{X}$ \\
\hline \multicolumn{6}{|l|}{ Coppel } \\
\hline Geupec & Bebidas & & & $\mathrm{X}$ & \\
\hline Posadas & Turismo & & & & $\mathbf{X}$ \\
\hline Santuis & Minería & & & $\mathrm{X}$ & $\mathbf{X}$ \\
\hline Canadá & Calzado & & & & \\
\hline Tablex & Alimentos & & & & \\
\hline Ceramic & Construcción & & $\mathbf{X}$ & $\mathbf{X}$ & $\mathbf{X}$ \\
\hline
\end{tabular}

Fuentes: Cuadros previos.

a Negocio principal.

${ }^{b}$ ADR, ADR y/o instrumentos do deuda. 
en la Bolsa de Valores de México, 35 transan en los mercados internacionales American Depository Receipts o Global Depository Receipts (ADR O GDR), sólo 20 están inscritas en la bolsa de valores de Nueva York y 13 ofrecieron otros instrumentos de deuda entre 1992 y 1993 (véanse cuadros 3 y 5).

Sólo 13 grupos tienen filiales y, con ello, actividades que generan valor agregado en su rubro en el exterior (cuadro 1). En total, 24 grupos han desarrollado acuerdos comerciales, de redes de manufactura y de mercados con empresas internacionales como clientes (véase cuadro 5). Entre los motivos identificados por Fujita (Taylor ed., 1993, pp. 11-14) para promover la inversión extranjera directa, las empresas mexicanas tienen una especial preocupación por mejorar su capacidad tecnológica y por aumentar la eficiencia con estrategias de racionalización de sus operaciones y de reducción de costos (Cemex y Vitro). Sin embargo, la búsqueda de mercadós y la inversión extranjera directa en actividades orientadas a la exportación se hacen más importantes para las empresas que operan en mercados locales saturados (Televisa, Synkro, Bimbo-Baird's). La búsqueda de recursos es considerablemente menos importante para las firmas mexicanas.

En suma, la trayectoria más frecuente es una combinación de dos estrategias: expansión al mercado internacional de valores y la formación de alianzas estratégicas. Como puede apreciarse en el cuadro 6 , de los 60 grupos de nuestra muestra 37 se han internacionalizado. De estas 37 empresas mexicanas, 25 combinan de alguna manera estas dos actividades. Seis grupos limitan su acción a estas áreas. A pesar de que las actividades que agregan valor no son parte de esta trayectoria, la interacción con los socios internacionales y con agentes de valores puede ser muy intensa, transformando profundamente su organización y estrategias empresariales. La mayoría de los grupos de distribución minorista más importantes han seguido esta evolución. Sólo seis grupos mexicanos combinan las 4 estrategias (cuadro 6).

$\mathrm{Al}$ comparar las empresas transnacionales mexicanas con las multinacionales del tercer mundo del decenio de 1960, (según Khan (ed., 1986)), se aprecian algunas diferencias considerables en cuanto a estrategias de inversión, emplazamiento, mecanismos de expansión e instrumentos de financiamiento. Mientras las últimas emplean estrategias defensivas para ampliarse a los mercados del tercer mundo y contrarrestar los efectos de las tendencias recesivas, como las medidas proteccionistas o tratan de reducir el riesgo con la diversificación regional, las primeras utilizan estrategias agresivas para penetrar en los mercados del primer mundo. ${ }^{23}$ Esto es, las empresas mexicanas apuntan a los mercados del primer mundo para convertirse en fuerzas internacionales en sus respectivas áreas de operación. Penetran los mercados del primer mundo, no por la vía de acuerdos con el gobierno, negociaciones $o$ joint ventures con los inversionistas de esas áreas, como lo hicieron antes las empresas multinacionales (Khan, ed., 1986), sino que con medidas complejas y agresivas que comprenden adquisiciones, compras hostiles, adquisiciones apalancadas, opciones de compra, alianzas estratégicas, demandas judiciales y otras maniobras legales o financieras. Para financiar la expansión, por lo general no dependen de sus propios recursos internos. En cambio, utilizan sofisticados instrumentos financieros desarrollados por poderosos agentes transnacionales que se han convertido en un enlace clave de todo proceso de internacionalización. Las adquisiciones, las alianzas estratégicas y otros proyectos de inversión se llevan a cabo con escaso o ningún nuevo capital mexicano, sino más bien con créditos puente combinados con ofertas de ADR y GDR, eurobonos y otros instrumentos que suponen bajos índices de apalancamiento y también un elevado potencial de generación de efectivo por parte de los grupos mexicanos en el decenio de 1980.

El impulso a la internacionalización constituye la estrategia de sobrevivencia en el contexto de una economía abierta orientada a la exportación y de la creciente integración con ios Estados Unidos y Canadá. Las condiciones nacionales $\mathrm{c}$ internacionales favorecen a aquellos grupos cuya ventaja competitiva está en bienes que demandan tecnología madura y estandarizada, donde han logrado alta productividad, principalmente aplicando estrategias de reducción de costos (Vitro, Cemex) (Taylor, ed., 1993). En otros casos, esto se logra donde por razones culturales sería muy difícil reemplazarlos (comercio minorista, programación de televisión). Y ésta es precisamente la mayor similitud con las empresas multinacionales del tercer mundo analizadas por Khan (ed., 1986).

Es así como aun cuando lleguen a ser internacionales, estas empresas de los países de menor desarrolo relativo exhiben debilidades y deficiencias. Ingre-

\footnotetext{
${ }^{23}$ Un estudio de Naciones Unidas (Taylor, ed,, 1993) señala también la mayor proporción de inversión extranjera directa canalizada de países del tercer mundo.
} 
san a rubros no líderes y altamente cíclicos de la economía mundial (cemento, acero, vidrio, petroquímica) donde tienen mayor posibilidad de competir a nivel mundial. La alianza estratégica Vitro-Corning, por ejemplo, estaba limitada, antes de su fracaso, a la división de artículos para el hogar y no incluyó productos de última generación como fibra óptica, donde Corning es productor de vanguardia. Pero aún en la producción de envases de vidrio tradicionales Vitro tuvo un traspié en 1996, cuando el grupo reportó pérdidas de más de 400 millones de dólares, retirándose por completo del mercado estadounidense después de vender a Anchor.

Muy pocas empresas transnacionales mexicanas se han volcado a sectores de tecnología más avanzada. Vitro estaba produciendo maquinaria y equipos para fabricar vidrio en sus filiales de los Estados Unidos (plantas de Anchor), sin embargo, como se mencionó, tuvo que vender todos sus intereses en ese país en 1996. Cemex, ICA, BI y GMD están investigando la producción de plantas de bajo impacto ambiental; Televisa ha comprado un satélite propio que obligará al grupo a involucrarse y asimilar la tecnología contenida en este producto. Y Carso Global Telecom empezó, en 1996, una agresiva expansión a actividades de multimedios con la adquisición de Prodigy Services.

La mejor valoración de las emisiones de deuda mexicana (eurobonos y títulos comerciales, entre otros) entre 1992 y 1994, se ha ajustado dramáticamente luego de la devaluación y colapso de diciembre de 1994. A partir de 1995, debieron ofrecerse tasas mucho más altas para compensar los mayores riesgos. Además, estos recién llegados al mercado internacional son más vulnerables a las estrategias financieras del mercado abierto c incluso de los inversionistas institucionales y de los especialistas en finanzas internacionales, que escrutan permanentemente sus decisiones y rendimientos, y pueden provocar inestabilidad en los precios de sus acciones y su situación financiera. Como suelen interesarse por la rentabilidad a corto plazo, ejercen presión sobre la empresa para que sacrifique sus estrategias de inversión de largo aliento, y promueven las prácticas especulativas.

(Traducido del inglés)

\section{Entrevistas}

1. Bufete Industrial

Licenciado Luis de la Mora

Subdirector de Recursos Financieros

2. Cemex

C.P. Víctor Naranjo

Director de Finanzas y Relaciones con

Inversionistas

3. Grupo Carso

Eduardo Valdés

4. Grupo Alfa

Ing. Enrique Flores

Director de Relaciones con Inversionistas

\section{Grupo Cifra}

Ing. Federico Casillas

Director de Relaciones con Inversionistas

\section{Grupo ICA}

Ing. Gerardo Sáez

Director de Relaciones con Inversionistas

7. Televisa

Manuel Abud

Director de Relaciones con Inversionistas

8. Vitro

Hugo Sánchez García

Director de Relaciones con Inversionistas 


\section{Bibliografía}

Alter, C. y J, Huge (1993): Organizations Working Together, Londres, Sage Publications.

América Economía \{1993-1994): Suplemento publicitario especial, Nueva York, World Financial Centre.

Aronson, J. D. y P. F. Cowhey (1993): Managing the World Economy, The Consequences of Corporate Alliances, Nueva York: Council on Foreign Relations Press.

Bibeault, D. B. (1982): Corporate Turnaround. How Managers Turn Around Losers into Winners, Nueva York, McGraw Hill Book Company.

Bleeke, J. y D. Ernst (1991): The way to win in cross-border alliances. Harvard Business Review, vol. 69. N" 6, Boulder, Colorado, Harvard University.

HMV/AMIB (Bolsa Mexicana de Valores/Asociación Mexicana de Intermediarios Bursátiles) (1996): México Company Handbook 1995-1996, México, O. F.

BMV (1994): Annual Meetings Reports and Offering Circulars, México, D.F,

Brock, J. W. y W. Adams (1989): Merger-mania: An empirical critique. D. L. McKee (ed.), Hostile Takeovers, Issues in Public and Corporate Policy, Londres, Praeger.

Bruning, E. R. (1989): The economic implications of the changing merger process, D. L. McKee (ed.), Hostile 'Takeovers, Issues in Public and Corporate Policy, Londres, Praeger.

Business Mexico (1993): México D.F., American Chamber of Commerce of Mexico, mayo.

(1994): México: D.F., American Chamber of Commerce of Mexico, enero.

Downes, J. J. y E. Goodman (1995): Dictionary of Finance and Investment Terms, Nueva York, Barrons.

Ejea, G., C. Garrido y C. Leriche (1992); Aspectos microfinancieros del cambio estructural: la banca y la bolsa. El cotidiano, México D.F., Universidad Autónoma Metropolitana (UAM), septiembre- octubre.

Eummoney (1993): Londres, Euromoney Publications, mayo.

Expansión (1992): vol. 24, N 601, México D.F., Expansión S.A., 14 de octubre.

(1994): vol. 26, N 650, México D.F, Expansión S.A., 28 de septiembre.

Financial Times (1992): Londres, 23 de julio.

Garrido, C. y E. Quintana (1987): Financial relations and economic power in Mexico. R. Anzaldúa Montoya y S. Maxfleld (eds.) Government and Private Sector in Contemporay México, California, Centre for US-Mexican Studies.

IMFF (1993): México, D.F., Instituto Mexicano de Ejecutivos de Finanzas, octubre.

International Financial Review (1992): Washington D.C., Fondo Monetario Internacional (I-MI), todos los números.

(1993): Washington D.C., Fondo Monetario Internacional (FMI), todos los números.

Journal of Commerce (1998): Nueva York, Harold Gold (ed.), 19 de mayo.
Jurgensen, E. (1993); Evolution, potential and challenges in North American cross-border mergers and acquisitions (The Mexican view), México D.F., Casa de Bolsa Vector mimen.

Khan, K. (ed.) (1986): Multinationals of the South: New Actors in the International Economy, Londres, Frances Pinter $\mathrm{Pu}-$ blishers.

Latin American Newsletters (1993): Latin American Regional Reports, Mexico and NAI-TA Report, Londres, 15 de abril.

Lorangc, P. y J. Roos (1992): Strategic Alliances: Formation. Implementation and Evolution. Cambridge, Massachusetts, Blackwell Business.

McKee, D. L. (ed.) (1989): Hostile Takeovers. Issues in Public and Corporate Policy, Londres, Praeger.

Michalet, C. (1991): Strategic partnerships and the changing internationalization process, L. K. Mylelka (ed.), Strategic Partnerships, Slate Firms and International Competition, Rutherford, New Jersey, Farilcigh Dickinson University Press.

Mytelka, Lynn K. (ed.) (1991): Strategic Partnerships, State Firms and International Competition, Rutherford, New Jersey, Farileigh Dickinson University Press

Peres Núñcz, W. (1993): Internacionalización de empresas industriales latinoamericanas, Revista de la CEPAL, $\mathrm{N}^{\circ} 49$, LC/G.1757-P, Santiago de Chile, Comisión Económica para América Latina y el Caribe (Ct,i>AL).

Salas-Porras, A. (1997): Estructuras, agentes y constelaciones corporativas en México durante la década de los noventa. Revista mexicana de sociología, vol. 59, $\mathrm{N}^{\circ} 4$, México D.F., Universidad Nacional Autónoma de México (UNAM).

Slatler, S. (1984): Corporate Recovery: Successful Turnaround Strategies and their Implementation, Middlesex, Penguin Books.

Taylor R. (ed,) (1993): 'Transnational Corporations from Developing Countries. Impact on Their Home Countries. Nueva York, Naciones Unidas, Division de Empresas Trailsnacionales y Gestión. Publicación de las Naciones Unidas, $\mathrm{N}^{\mathrm{D}}$ de venta E.93.II.A.8.

The New York Times (1989); Nueva York, 30 de octubre.

Trevor, L, B. (1989): Hostile takeovers: A US Falkland Islands where the Argentines always win, D, L. McKee (cd.), Hostile Takeovers. Issues in Public and Corporate Policy, Londres, Praeger.

Tseng, C. (1994): The process of internationalisation of PRC Multinationals, H. Schütte (ed.), The Global Competitiveness of the Asian Firm, Nueva York, St. Martin's Press,

Useem, M, (1993): Shareholder power and the struggle for corporate control, 14. Swedberg (ed.), Explorations in Economic Sociology, New York, Russet Sage Foundation.

Vedder, R, K. (1989): Three Cheers for the corporate raider, D.L. McKee (ed.). Hostile Takeovers. Issues in Public and Corporate Policy, Londres, Praeger.

Vitro (1993): Annual Meeting Report, México D.F.

Wall Street Journal (1987): Nueva York, Frederick Taylor (ed.), 30 de julio.

(1989): Nueva York, Frederick Taylor (ed.), 11 de septiembre. 